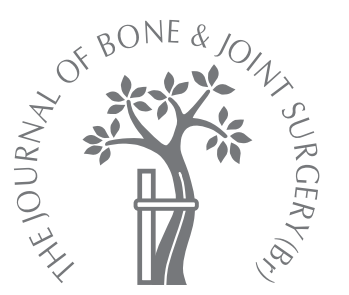

V. K. Eswaramoorthy, L. C. Biant, R. E. Field

From the Elective Orthopaedic Centre, Epsom, England

V. K. Eswaramoorthy, MRCS Clinical Research Fellow

R. E. Field, PhD, FRCS, FRCS(Orth), Consultant Orthopaedic Surgeon and Director of Research

Research \& Education

South West London Elective

Orthopaedic Centre, Dorking

Road, Epsom, Surrey KT18 7EG, UK.

L. C. Biant, MS, FRCS Ed(Trauma \& Orth), Consultant Trauma and Orthopaedic Surgeon

Royal Infirmary of Edinburgh, Little France Crescent, Old Dalkeith Road, Edinburgh EH16 4SA, UK.

Correspondence should be sent to Dr V. K. Eswaramoorthy; e-mail: vasanth22@yahoo.com

(C)2009 British Editorial Society of Bone and Joint Surgery doi:10.1302/0301-620X.91B11. $22651 \$ 2.00$

$J$ Bone Joint Surg [Br] 2009;91-B:1454-8. Received 30 March 2009; Accepted after revision 30 June 2009

\section{Clinical and radiological outcome of stemmed hip replacement after revision from metal-on-metal resurfacing}

We report the outcome of total hip replacement in 29 failed metal-on-metal resurfacing hip replacements in which the primary surgery was performed between August 1995 and February 2005. The mean length of follow-up was five years (1.7 to 11.7). Of the 29 hip resurfacings, 19 acetabular components and all the femoral components were revised (28 uncemented stems and one cemented stem). There were no deaths and none of the patients was lost to follow-up. None of the hips underwent any further revision. The results of the revision resurfacing group were compared with those of a control group of agematched patients. In the latter group there were 236 primary total hip replacements and 523 resurfacings performed during the same period by the same surgeons.

The outcome of the revision resurfacing group was comparable with that of the stemmed primary hip replacement group but was less good than that of the primary hip resurfacing group. Long-term follow-up is advocated to monitor the outcome of these cases.

Advocates of hip resurfacing suggest that this type of replacement can be revised to a standard primary total hip replacement (THR). ${ }^{1-3}$ If this is correct, resurfacing should maximise the total prosthetic joint life available to the patient. However, this rationale assumes that the patient will enjoy additional years of good outcome, after revision to a THR, and that the results of the 'revision primary' will not be compromised by the resurfacing which preceded it.

At present, there is little information on the outcome of revision after resurfacing. We therefore report the medium-term results of a series of such cases and compare the outcome with that obtained by patients with different categories of standard primary THR.

\section{Patients and Methods}

Our joint replacement surveillance programme monitored the outcome of the 1998 THRs undertaken at our hospitals between January 1995 and December 2003. The review programme is run by dedicated staff and is independent of any continuing care provided by the patients' designated surgeon. Until January 2007, formal clinical and radiological evaluations were undertaken at two, five and ten years after the initial surgery. Postal review has been undertaken annually since 1999, using the postal Oxford hip score (OHS) questionnaire 4 and is ongoing.
Radiological examinations were undertaken using the protocol described by Singh et $\mathrm{al}^{5}$ and evaluated using the standardised system described by Johnston et al. ${ }^{6}$ Acetabular radiolucent lines were measured according to the zones described by DeLee and Charnley. ${ }^{7}$ Femoral radiolucent lines were analysed as described by Gruen, McNeice and Amstutz. ${ }^{8}$ A radiolucent line was recorded only if it occupied at least $50 \%$ of the zone. Migration of the acetabular component was measured using the interteardrop line and Kohler's line as reference. ${ }^{9}$ Migration of the acetabular component was defined as significant if there was a $>3 \mathrm{~mm}$ linear change (medial, superior, or both) in relation to either Kohler's or the inter-teardrop line. Heteroptopic ossification was evaluated using the criteria described by Brooker et al. ${ }^{10}$ The acetabular inclination angle was measured on a post-operative standing pelvic radiograph.

Between August 1995 and February 2005, 558 metal-on-metal hip resurfacings were undertaken in 504 patients by two surgeons (REF, TGK). These involved 334 men (368 hips) and 170 women (190 hips). A total of 29 hips $(5.2 \%)$ in 28 patients was revised to a stemmed primary THR between April 1997 and August 2007.

The indication for revision surgery was pain without radiological evidence of failure in 11 hips, suspected loosening of the femoral component in seven, fracture of the femoral 
Table I. Details of the revision components

\begin{tabular}{lcc}
\hline Revision implant & Acetabular component retained & Acetabular component revised \\
\hline Trident acetabular component and Accolade stem $^{*}$ & 0 & 4 \\
Trident acetabular component with ABG II stem $^{*}$ & 0 & 4 \\
Synergy stem $^{\dagger}$ & 5 & 0 \\
Reflection acetabular component with Synergy stem $^{\dagger}$ & 0 & 1 \\
ANCAfit system $^{\ddagger}$ & 2 & 9 \\
Anthology stem $^{\dagger}$ & 2 & 0 \\
Allofit acetabular component with CF 30 stem $^{\S}$ & 0 & 1 \\
Tritaper $^{\dagger}$ & 1 & 0 \\
Total $^{*}$ & 10 & 19 \\
\hline * Stryker, Mahwah, New Jersey & & \\
† Smith \& Nephew, Warwick, United Kingdom & & \\
‡ Wright Medical, Arlington, Tennessee & & \\
§ Zimmer-Sulzer, Winterthur, Switzerland & &
\end{tabular}

neck in four, suspected loosening of the acetabular and femoral component in three, suspected loosening of the acetabular component in two, deep infection in one and a mass in the groin in one.

The revised resurfacings comprised 23 Birmingham Hip Resurfacings (BHR, Smith and Nephew, Warwick, United Kingdom), four McMinn resurfacings (Corin, Cirencester, United Kingdom), one Conserve Plus (Wright Medical, Arlington, Tennessee) and one Cormet 2000 (Corin).

The mean age at resurfacing was 50.9 years (21 to 65) with a mean time to revision of 42 months ( 4 to 102) and involved 20 women (21 hips) and eight men (eight hips). The mean age at revision was 54.4 years (21 to 70 ). In ten hips, the acetabular component was retained and the femoral component was revised to a stemmed implant with an appropriately-sized metal head. The remaining 19 hips had both components revised to a conventional stemmed THR. In 18 of these cases, a ceramic-on-ceramic bearing couple was used and a Metasul (Sulzer, Winterthur, Switzerland) metal-on-metal bearing couple in one hip. The details of the revised components are given in Table I.

When the acetabular component had to be removed, the Explant system (Zimmer, Warsaw, Indiana) was used to minimise bone loss. Of the 19 hips in which the acetabular component was revised, the revision primary acetabular component was of identical external diameter in five, $2 \mathrm{~mm}$ larger in six, $4 \mathrm{~mm}$ larger in four and $6 \mathrm{~mm}$ larger in four. Reaming was undertaken cautiously to avoid unnecessary enlargement of the acetabulum although in ten cases bone grafting was required. Morcellised allograft was used in seven hips and Allomatrix putty (Wright Medical) in three.

The acetabular component was revised in all the 11 patients presenting with pain without radiological evidence of loosening. Of these six had inflammatory synovitis at revision. Histological examination of the synovial tissue showed lymphocytic infiltration with foreign body giant cells and haemosiderin-laden histiocytes consistent with metal sensitivity. The median size of the acetabular component in the patients who underwent revision for pain was $52 \mathrm{~mm}$ (48 to 60$)$.

The patient with a mass in the groin has been reported previously. ${ }^{11}$ This patient underwent excision of the mass 32 months after hip resurfacing. At operation, a necrotic mass was seen within the psoas sheath not extending above the inguinal ligament. The patient had persistent pain after excision of the mass. Revision of resurfacing to a stemmed ceramic-on-ceramic THR was undertaken 4.5 years after primary resurfacing. Intra-operatively, there was florid synovitis extending to the psoas tendon and muscle necrosis. Histological examination of the synovium and the muscle showed areas of necrosis with dense infiltration of lymphocytes, giant cells and histiocytes consistent with an aseptic lymphocytic vasculitis associated lesion (ALVAL)-type response. $^{12}$

Two orthopaedic surgeons (REF, TGK) undertook all the revision procedures which were performed in laminarairflow operating theatres, with the patients in the lateral decubitus position. The posterior approach was used for all the revision procedures.

In ten hips the acetabular component was retained with the stability of the component confirmed intra-operatively. All the patients were given three doses of cefuroxime (750 mg) intravenously as antibiotic prophylaxis and thromboprophylaxis with subcutaneous low-molecularweight heparin once daily for five days after surgery.

In 28 patients mobilisation involved unrestricted weight-bearing from the first post-operative day but the remaining patient was mobilised non-weight-bearing for six weeks since the acetabular osteolysis required extensive bone grafting.

For non-randomised comparison groups, we measured OHS in 209 patients (236 hips) with primary THR with a mean age of 54.7 years (27 to 62 ) and 467 patients with resurfacing (523 hips) with a mean age of 54.2 years (17 to 72 ). Their operations had been performed by the same surgeons during the same period as the revision resurfacing procedures. 


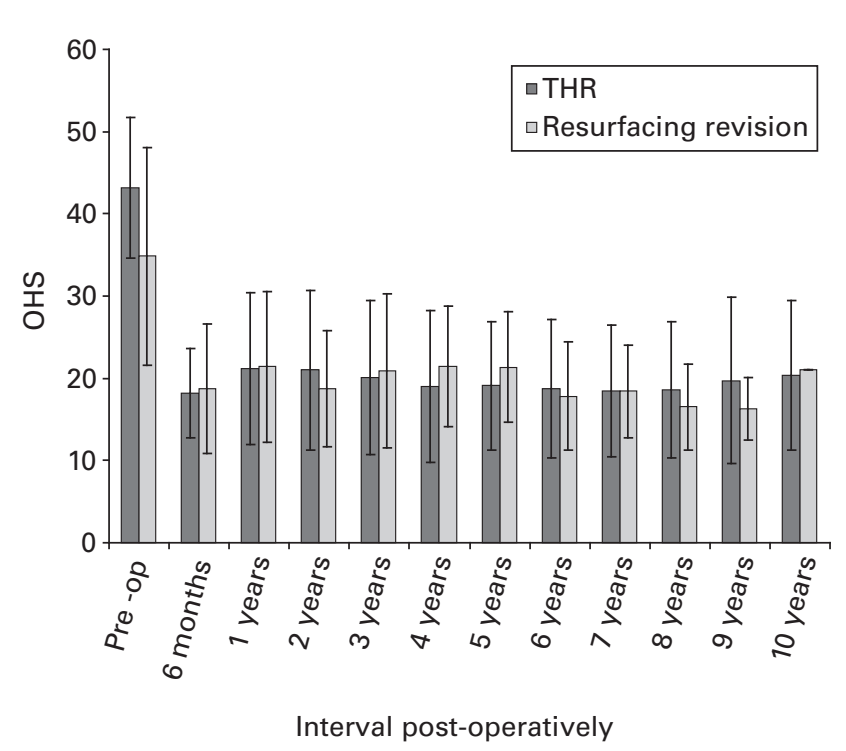

Fig. 1

Bar chart showing the mean Oxford hip score (OHS) of the primary total hip replacement (THR) and resurfacing revision groups. Whiskers indicate SD.

Statistical analysis. Analysis of the outcome scores was performed using Graph Pad Prism software version 5.0 for Windows (Graph Pad Software Inc., San Diego, California), using a two-sample $t$-test. A p-value $\leq 0.05$ was taken to be statistically significant.

\section{Results}

The mean follow-up was five years (1.7 to 11.7$)$. There were no deaths and none of the patients was lost to follow-up.

Oxford Hip Scores. The mean yearly OHS for the study and the control groups throughout the follow-up period is shown in Figures 1 and 2. The number of scores available at each yearly interval is shown in Figure 3.

The mean OHS of the revision resurfacing group was 21.3 (14 to 31 ). The mean score of the revision group fell within the expected range after primary THR. However, the resurfacing group performed better than the revision primary group.

No significant statistical difference was found between the mean OHS of the revision resurfacing group and that of the primary THR group ( $t$-test, $\mathrm{p}=0.420)$. However, there was significant difference between the mean OHS of the revision resurfacing group and that of the primary resurfacing group up to four years post-operatively $(\mathrm{p}=0.019)$. Beyond four years, the difference was not statistically significant $(\mathrm{p}=0.2002)$.

Radiological findings. Three of the 27 uncemented stems had a non-progressive reactive line in one zone. However, all the stems and acetabular components were stable and osseointegrated. No radiolucent line was found on radiological examination of the two cemented components. A total of

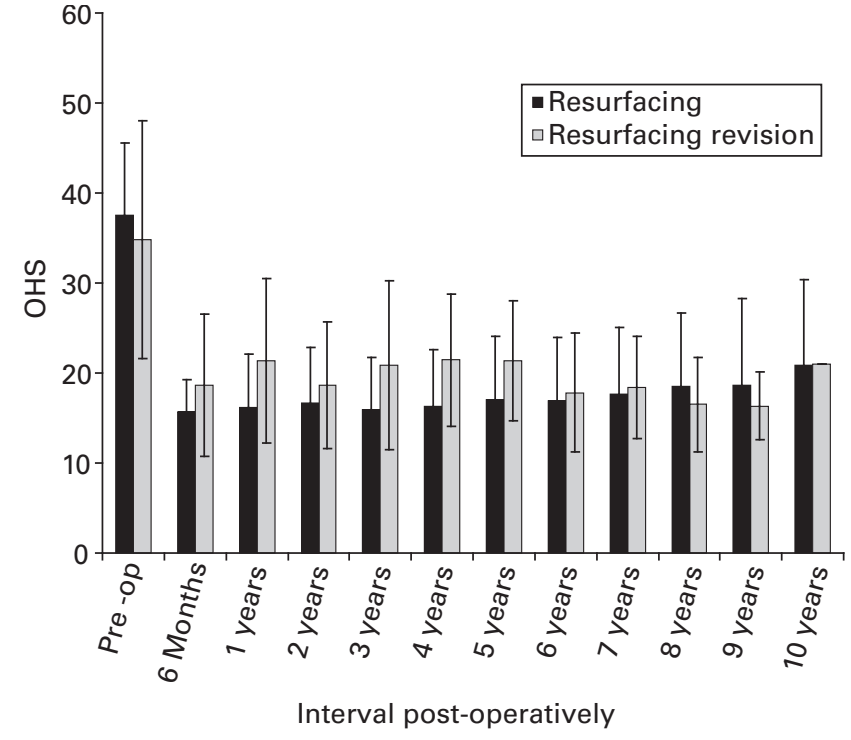

Fig. 2

Bar chart showing the mean Oxford hip score (OHS) of the resurfacing and resurfacing revision groups. Whiskers indicate SD.

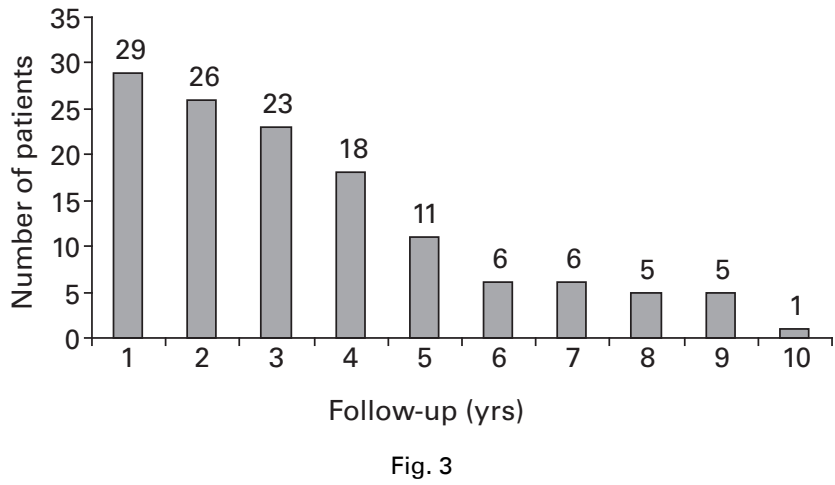

Bar chart showing the number of Oxford hip scores (OHS) scores for the revision resurfacing group available at each time point.

28 stems were in a neutral position and one was in $4^{\circ}$ of varus. There was no radiological evidence of migration in any of the hips. The mean inclination angle of all acetabular components was $42^{\circ}\left(25^{\circ}\right.$ to $\left.60^{\circ}\right)$. There was no evidence of the formation of heterotopic bone in any of the hips.

Complications. There were no complications intraoperatively and no cases of dislocation, deep infection, periprosthetic fracture or nerve palsy. No patient has required re-revision.

Re-operations. One patient underwent exploration of the groin for persistent pain. There was no radiological evidence of loosening of the component and the inflammatory markers (ESR, CRP, WC (count)) and an isotope bone scan of the hips were normal. There was no evidence of 
impingement on fluoroscopic screening intra-operatively. Lax anterior fibres of the conjoint tendon were strengthened.

\section{Discussion}

We believe that our study is the largest reporting the outcome after revision of hip resurfacings. Most of the revision resurfacing procedures were undertaken in women (21 hips). The rate of revision resurfacing was $11 \%$ (21 of 190 hips) for women as opposed to $2 \%$ ( 8 of 368 ) for men. This is consistent with recent reports of a higher rate of revision in women. ${ }^{13-15}$

The resurfacing group had significantly lower preoperative mean OHS than patients undergoing stemmed primary THR $(t$-test, $\mathrm{p}=0.004)$. This suggests that patients undergoing hip resurfacing are having joint replacement at an earlier stage in their functional decline than those being treated by stemmed primary THR. Our data did not identify whether this difference was driven by patient demand or surgeon recommendation. The mean post-operative OHS of our series fell within the expected range of that after a primary THR in an elderly matched population, undertaken during the same period, by the same surgeons.

A limitation of our study was that the duration of followup remained relatively short. This was unavoidable since the current-generation resurfacings have only been in use for just over a decade and relatively few revisions have been undertaken. Our data were cross-sectional and the patients had revisions at different time points. However, previous work on OHS has shown that large-volume cross-sectional data are statistically comparable with longitudinal data in our series of patients. ${ }^{16}$

Revision of failed metal-on-polyethylene resurfacings implanted during the 1970s and 1980s was complicated because preparation for implantation of the polyethylene components necessitated extensive acetabular reaming and the reduced thickness and increased flexibility of these acetabular components led to higher rates of wear and massive osteolysis. ${ }^{17-21}$ In our series 19 acetabular components were revised. In 11 hips, the external diameter of the revision implant was not more than $2 \mathrm{~mm}$ greater than in the original and in only four hips did the increase exceed $4 \mathrm{~mm}$. While some type of graft was used in ten cases, standard primary uncemented components were used in all and good osseo-integration was confirmed in all cases.

The literature contains relatively few reports on the clinical outcome of hip replacement after failed hip resurfacing. 1,2.22,23 Of these, three reports were published in the 1980s and relate to revision of metal-on-polyethylene resurfacing implants. The key observations of these studies were that the revision procedure was more straightforward than a conventional revision on the femoral side, but not necessarily on the acetabular side. With regard to outcome, the authors identified that the resurfacing revisions performed better than standard revisions, but they did not report how the resurfacing revisions compared with the original resurfacings or stemmed primary THRs.
With regard to the current generation of metal-on-metal resurfacing implants, Ball et $\mathrm{al}^{2}$ reported the results of a match-paired analysis of 21 conversions of failed femoral components in metal-on-metal hip resurfacing arthroplasties and 58 primary THRs. The indication for conversion was fracture of the femoral neck in five and loosening of the femoral component in 16 . In 18 hips, the acetabular component was retained. The remaining three required revision of the acetabular side since a matching femoral head was unavailable. At a mean of 46 months, the functional and radiological outcome was comparable and no other differences were seen between the two groups.

In our study, the original resurfacing acetabular component was retained in only ten of 29 hips. This represents the more diverse spectrum of failure now reported by users of metal-on-metal resurfacings.

We have shown that for the current generation of metalon-metal resurfacing patients, the clinical outcome of revision to a stemmed THR may be less good than the original resurfacing, but does equate to that of a stemmed primary THR, in age-matched individuals. However, it will require the results of long-term studies to confirm that clinical performance is maintained and registry data to show that these resurfacing revisions last as long as standard primary THRs.

We thank Mrs J. Riordan and Mrs S. Grice for running the Joint Replacement Review Programmes at St. Helier Hospital and St. Anthony's Hospital, respectively. Their dedication and diligence have ensured that we were able to undertake this review. We also thank Mr T. G. Kavanagh for allowing us to include his patients in this review.

No benefits in any form have been received or will be received from a commercial party related directly or indirectly to the subject of this article.

\section{References}

1. Bradley GW, Freeman MA. Revision of failed hip resurfacing. Clin Orthop 1983;178:236-40.

2. Ball ST, Le Duff MJ, Amstutz HC. Early results of conversion of a failed femoral component in hip resurfacing arthroplasty. J Bone Joint Surg [Am]2007;89-A:735-41.

3. Shimmin A, Beaulé PE, Campbell P. Metal-on-metal hip resurfacing arthroplasty. J Bone Joint Surg [Am] 2008;90-A:637-54.

4. Dawson J, Fitzpatrick R, Carr A, Murray D. Questionnaire on the perceptions of patients about total hip replacement. J Bone Joint Surg [Br] 1996;78-B:185-90.

5. Singh PJ, Marsh AJ, Kerry SM, Field RE. Measurement of femoral stem migration: a validation study. J Bone Joint Surg [Br] 2004;86-B:76.

6. Johnston RC, Fitzgerald RHJ, Harris WH, et al. Clinical and radiographic evaluation of total hip replacement: a standard system of terminology for reporting results. J Bone Joint Surg [Am] 1990;72-A:161-8.

7. DeLee JG, Charnley J. Radiological demarcation of cemented sockets in total hip replacement. Clin Orthop 1976;121:20-32.

8. Gruen TA, McNeice GM, Amstutz HC. "Modes of failure" of cemented stem-type femoral components: a radiographic analysis of loosening. Clin Orthop 1979;141:1727

9. Nunn D, Freeman MA, Hill PF, Evans SJ. The measurement of migration of the acetabular component of hip prostheses. J Bone Joint Surg [Br] 1989;71-B:629-31.

10. Brooker AF, Bowerman JW, Robinson RA, Riley LH Jr. Ectopic ossification following total hip replacement: incidence and a method of classification. J Bone Joint Surg [Am] 1973;55-A:1629-32.

11. Boardman DR, Middleton FR, Kavanagh TG. A benign psoas mass following metal-on-metal resurfacing of the hip. J Bone Joint Surg [Br] 2006;88-B:402-4.

12. Davies AP, Willert HG, Campbell PA, Learmonth ID, Case CP. An unusual lymphocyte perivascular infiltration in tissues around contemporary metal-on-metal joint replacements. J Bone Joint Surg [Am] 2005;87-A:18-27. 
13. Steffen RT, Pandit HP, Palan J, et al. The five-year results of the Birmingham Hip Resurfacing arthroplasty: an independent series. J Bone Joint Surg [Br] 2008;90B:436-41.

14. De Haan R, Campbell PA, Su EP, De Smet KA. Revision of metal-on-metal resurfacing arthroplasty of the hip: the influence of malpositioning of the components. $J$ Bone Joint Surg [Br] 2008;90-B:1158-63.

15. Ollivere B, Darrah C, Barker T, Noland J, Porteous MJ. Early clinical failure of the Birmingham metal-on-metal hip resurfacing is associated with metallosis and soft-tissue necrosis. J Bone Joint Surg [Br]2009;91-B:1025-30.

16. Field RE, Cronin MD, Singh PJ. The Oxford hip scores for primary and revision hip replacement. J Bone Joint Surg [Br] 2005;87-B:618-22.

17. Ahnfelt L, Herberts $\mathbf{P}$, Malchau H, Andersson GB. Prognosis of total hip replacement: a swedish multicenter study of 4664 revisions. Acta Orthop Scand Suppl 1990;238:1-26.
18. Bell RS, Schatzker J, Fornasier VL, Goodman SB. A study of implant failure in the Wagner resurfacing arthroplasty. J Bone Joint Surg [Am] 1985;67-A:1165-75.

19. Head WC. Wagner surface replacement arthroplasty of the hip: analysis of fourteen failures in forty-one hips. J Bone Joint Surg [Am] 1981;63-A:420-7.

20. Howie DW, Campbell D, McGee M, Cornish BL. Wagner resurfacing hip arthroplasty: the results of one hundred consecutive arthroplasties after eight to ten years. J Bone Joint Surg [Am] 1990;72-A:708-14.

21. Howie DW, Cornish BL, Vernon-Roberts B. Resurfacing hip arthroplasty: classification of loosening and the role of prosthesis wear particles. Clin Orthop 1990;255:144-59

22. Capello WN, Trancik TM, Misamore G, Eaton R. Analysis of revision surgery of resurfacing hip arthroplasty. Clin Orthop 1982;170:50-5.

23. Thomas BJ, Amstutz HC. Revision surgery for failed surface arthroplasty of the hip Clin Orthop 1982;170:42-9 